\title{
Mutations associated with drug resistance and prevalence of vaccine escape mutations in patients with chronic hepatitis $B$ infection
}

\author{
Maria Isabel Magalhães A. dos Santos ${ }^{1}$ (iD $\quad$ | Sidelcina Rugieri Pacheco ${ }^{1}$ | \\ Andreas Stocker $^{2}$ | Maria Isabel Schinoni ${ }^{3}$ | Raymundo Paraná ${ }^{3}$ | \\ Mitermayer G. Reis ${ }^{1}$ | Luciano K. Silva ${ }^{1}$
}

${ }^{1}$ Centro de Pesquisas Gonçalo Moniz, Fundação Oswaldo Cruz (FIOCRUZ), SalvadorBA, Brazil

2 Laboratório do Serviço de GastroHepatologia/de Pesquisa em Infectologia (SGH/LAPI), HUPES-UFBA, Salvador-BA, Brazil

${ }^{3}$ Universidade Federal da Bahia, Ambulatório Magalhães Neto, HUPES-UFBA, Salvador-BA, Brazil

\section{Correspondence}

Maria Isabel Magalhães Andrade dos Santos, Msc, Pathology and Molecular Biology lab at Gonçalo Moniz Research Centre, FIOCRUZBA, R. Waldemar Falcão, 121, Candeal, Salvador-BA 40296-710, Brazil.

Email: mariaisabel_mas@yahoo.com.br

\section{Funding information}

Científico e Tecnológico - Universal-MCTI/

CNPq, Grant number: process: $478322 /$

2012-7; Instituto Gonçalo Moniz - FIOCRUZ

- BA/BRAZIL, Grant number: 14/2012
Conselho Nacional de Desenvolvimento

The Brazilian public health system (SUS) has provided antiviral drugs for chronic hepatitis $\mathrm{B}$ treatment for over 10 years, but a system for monitoring for drug-related resistance mutations is not available. Determine the presence of HBV mutations associated with resistance to nucleos(t)ide analogs among 81 patients with chronic HBV infection in Salvador-BA-Brazil. HBV-DNA was PCR amplified with primers deduced from the rt domain at the HBV P gene, the sequence extended $1032 \mathrm{bp}$ (from amino acid 1 to $344-r t$ domain). Those sequences were submitted to the HBV drug resistance database to retrieve each mutation according to the genotype. HBV genotype A1 (85.2\%) was the most prevalent, followed by genotype A2 (4.9\%), F (6.2\%), and $\mathrm{C} 1, \mathrm{D} 2$, and D4 (1.2\% each). Six patients (7\%) exhibited resistance mutations to LAM, ETV, and TDF: two with patterns L180M + M204V and four with other different patterns: L80I + L180M + M204I; L80V + L180M + M204V; M204I; A194T. All of these mutations were present in patients with genotype $A$ (four $A 1$ and two A2). In addition, four mutations in gene $S$ (three cases with the sl195M mutation and one with the W196L mutation), were detected, corresponding to a rate of $6 \%$ of vaccine escape mutations. Althougth the small sample size, an association was found between the occurrence of HBV resistance mutations and HBeAg positivity, coinfection with HIV and a history of treatment for HBV and/or HIV.

KEYWORDS

$\mathrm{HBV}$, hepatitis $\mathrm{B}$ virus, nucleos(t)ides analogs, resistance

\section{1 | BACKGROUND}

Ethical approval: Ethics Committee for Research Involving Human Subjects of CPqGM/ FIOCRUZ- BA - number: 238/2011.

Ethics Committee for Research Involving Human Subjects of HUPES-UFBA - number: 31177 - CAAE: 01315812.0.0000.0049.

Although the safety and efficacy of vaccines, infections with hepatitis $B$ virus (HBV) is a public health problem, mainly, being one of the leading causes of death from infectious disease worldwide. ${ }^{1-3}$

The HBV belongs to the Orthohepadnavirus genre of Hepadnaviridae family. It has partially double-stranded DNA genome of approximately 3200 nucleotides (nts.). Errors promoted by reverse 
transcriptase during replication generate are at a rate of approximately 1.4 and $3.2 \times 10-5$ substitutions of nucleotides (nt.) per year. ${ }^{4}$ This rate is considered the highest among DNA virus genomes. ${ }^{5}$ This phenomenon is responsible to form heterogeneous groups of sequences of the viral genome in the same host, known as viral quasispecies.

Under the action of antiviral drugs, the quasispecies population can evolve through the selection of resistant HBV mutant forms due to the drugs. Therefore, viral mutations have virological, laboratory, and clinical effects that can ultimately determine the therapeutic failure. ${ }^{6,7}$

In the last 20 years, significant advances in the treatment of chronic hepatitis $B$ have occurred, initially by the use of interferonalpha (INF-alpha). The INFs have restricted its use due to high cost and mainly because of its side effects. This limitation does not occur with the use of nucleos(t)ide analogs. However, the extended use of nucleos $(\mathrm{t})$ ide analogs can determine the emergence of drug-resistant (eg, YMDD mutant) strains. ${ }^{8}$

The international scientific literature has supported research on screening for genotypic resistance of HBV variants that do not correspond to those found in Brazil. Therefore, this study may contribute to the association of resistance for the genotypes $\mathrm{A} 1$ and $\mathrm{F}$.

\section{2 | OBJECTIVES}

The purpose of study was to determine the presence of HBV mutations associated with resistance to nucleos(t)ide analogs among 81 patients with chronic HBV infection at the Hospital Universitário Professor Edgard Santos, Salvador-BA-Brazil.

\section{3 | STUDY DESIGN}

\subsection{Study sites and samples}

The study was conducted at the Centro de Pesquisas Gonçalo Moniz (FIOCRUZ-BA), Salvador-BA, in collaboration with the Hepatology Service of Ambulatório Magalhães Neto, Hospital Universitário Prof. Edgar Santos of the Universidade Federal da Bahia (HUPES-UFBA), Salvador-BA, the Research Laboratory of Infectious Diseases (LAPIBA), Salvador-BA and the Central Public Health Laboratory (LACENBA), Salvador-BA.

We recruited all HBV DNA detectable (viral load above 160 copies $/ \mathrm{mL}$ ) patients being accompanied at the Hospital Professor Edgar Santos who made blood draw to evaluate the viral load in the period from July 2012 to May 2015, for the presence of AgBHs for more than 6 months, and with a confirmatory molecular test represented by a HBV-DNA qualitative. These patients were naïve or treated with nucleos(t)ide analogues (LAM, ETV, ADV, and TDF), and agreed to participate by signing the TCLE that was approved by the Ethics Committee for Research Involving Human Subjects of FIOCRUZ-BA and HUPES-UFBA.

\subsection{Collection and storage of data and samples}

Data from interviews and reviews of medical records were registered in a database protected by password, available at FIOCRUZ, and accessible only by members of the research team (REDCap, Vanderbilt Univerity). A blood sample was collected from each participant to carry out the HBV viral load with COBAS ${ }^{\circledR}$ TaqMan kit (Roche, $\mathrm{CHE}$ ) and the analysis of resistance mutations. The samples were processed within $2 \mathrm{~h}$ from the collection by serum separation, then aliquoted and frozen in a freezer at $-80^{\circ} \mathrm{C}$ until use, to prevent degradation of viral DNA.

\subsection{HBV- DNA isolation and sequencing of amplicon.}

Total DNA was extracted from $200 \mathrm{~mL}$ of each serum sample using the High Pure Viral Nucleic Acid Kit (Roche, CHE) according to the manufacturer's instructions. Two overlapping regions comprising the whole area of rt were amplified using primers, CF and S-R2A, and RTF4 and RT-3a.A, the amplification using the primes CF and S-R2A was performed with a volume of $60 \mathrm{uL}$ containing $5 \mathrm{uL}$ of the extracted DNA, $1 \times$ PCR buffer without MgCl2-, $0.20 \mathrm{~mm}$ of each dNTP, $1.5 \mathrm{MgCl}$ 2, $0.3 \mathrm{mM}$ of each primer and 0.02 U/uL Taq Polymerase Platinum. The reagent mixture was heated at $94^{\circ} \mathrm{C}$ for $2 \mathrm{~min}$; followed by 40 cycles of denaturation at $94^{\circ} \mathrm{C}$ for $20 \mathrm{~s}$, annealing at $57^{\circ} \mathrm{C}$ for $30 \mathrm{~s}$ and extension at $72^{\circ} \mathrm{C}$ for $60 \mathrm{~s}$; and finally one more step at $72^{\circ} \mathrm{C}$ for $5 \mathrm{~min}$ to finish the extension of the tapes that were already amplified. RT-PCR amplification with these primers F4 and RT-3a was carried out with $60 \mathrm{uL}$, with the same reaction conditions, but with the proposed annealing temperature of $59^{\circ} \mathrm{C}$.

The amplified products were subjected to electrophoresis on agarose $1 \%$ gel, prestained with SYBR Safe (Invitrogen) and visualized with the transilluminator under blue light.

Purification of PCR products was performed using the PureLink PCR Purification Kit (Invitrogen, Carlsbad, CA, EUA) according to the manufacturer's instructions. The material was sent for sequencing of the polymerase gene through the BigDye Terminator method (ABI 3730).

\section{4 | Assembling sequence and determination of HBV genotypes}

The sequences of at least four (max. six) of each isolate were assembled along with a reference sequence of the genotype $A 1$ or $F$ (Genbank accession number AB116092 and AY090459, respectively). Analyses were performed using software CLC Main Workbench v.6.9 by visual inspection of electropherograms and correction of conflicting sites. For this analysis, we used the function "assemble sequences to reference" and the program's default parameters. The contigs had a size of $1032 \mathrm{bp}$ (corresponding to amino acids 1-344 of the RT HBV). ${ }^{10}$ The consensus sequence of each isolate was compared to a reference $\mathrm{HBV}$ sequence available in the DB HBVrt database ${ }^{11}$ for genotyping. The sequences were also analyzed in the MEGA program V.5.05 through the Neighbor-Joining algorithm (NJ) and 100 bootstrap replicates using analysis (Tamura $\mathrm{K}$ 2011). 
TABLE 1 Demographic and clinical characteristics at admission of patients with chronic hepatitis B treated at HUPES, 2012-2015

\begin{tabular}{|c|c|c|c|c|c|c|}
\hline \multirow[b]{3}{*}{ Characteristics on admission } & \multicolumn{4}{|c|}{ Treatment history } & & \\
\hline & \multicolumn{2}{|l|}{ Naive } & \multicolumn{2}{|l|}{ Treated } & \multicolumn{2}{|l|}{ Total } \\
\hline & $N=55^{\mathrm{a}} \quad(\%)$ & Average $\pm \mathrm{DP}$ & $N=18^{a}(\%)$ & Average $\pm \mathrm{DP}$ & $N=73^{a} \quad(\%)$ & Average $\pm \mathrm{DP}$ \\
\hline \multicolumn{7}{|l|}{ Sex } \\
\hline Male.:Fem. & $27: 28(49: 51)$ & & $14: 4(78: 22)$ & & $41: 32(56: 44)$ & \\
\hline \multicolumn{7}{|l|}{ Serology pos. } \\
\hline $\mathrm{AgHBe}$ & $5 / 45(11)$ & & $11 / 15(73)$ & & $16 / 60(27)$ & \\
\hline anti-HCV & 1/39 (3) & & $0 / 16(0)$ & & $1 / 55(2)$ & \\
\hline anti-HIV & $0 / 28(0)$ & & $3 / 13(23)$ & & $3 / 41(7)$ & \\
\hline \multicolumn{7}{|l|}{ Biopsy/elastography } \\
\hline FO & $3 / 8(37)$ & & $0 / 7(0)$ & & $3 / 15(20)$ & \\
\hline F1-F3 & $5 / 8(63)$ & & $7 / 7(100)$ & & $12 / 15(80)$ & \\
\hline F4 & $0 / 8(0)$ & & $0 / 7(0)$ & & $0 / 15(0)$ & \\
\hline Steatosis & $13 / 25(52)$ & & $3 / 7(43)$ & & $16 / 32(50)$ & \\
\hline
\end{tabular}

$\mathrm{DP}=$ standard deviation.

${ }^{\text {a } T o t a l ~ v a r y ~ d e p e n d i n g ~ o n ~ a v a i l a b i l i t y ~ o f ~ d a t a . ~}$

\subsection{Analysis of resistance mutation of RTHBV gene}

The antiviral resistance mutations for chronic hepatitis $B$ located in rtHBV L80V/I, V84M, I169T, V173L, L180M, A181V/T, T184G, A194T, S202G/I, M204I/V/S, I233V, N236T, and M250V were reviewed using an online tool available in the rtHBV DB database (Stanford University). ${ }^{11}$ This software also allows searching for mutations that impact on vaccine escape mutations associated with the rt, located in the S gene rtM204I (sW196*/S/G), rtM204V (sl195M) + rtM204V rtL180M/I (no mutations rtL180M), or rtV173L + rtL180M + rtM204V/I (sE164D, sl195M).

\section{6 | Data analysis}

Statistical analysis was performed using SPSS 21 program (IBM, IRL). The events of interest were reported with mean and standard deviation. To compare proportions, the Chi-square test (corrected by Yates) or Fisher's exact test were used when recommended. The odds ratio (OR) was calculated using the method of cross-products. In all statistical tests, a significance level of $5 \%(P<0.05)$ was used.

\section{4 | RESULTS}

A total of 81 patients had a viral load above 160 copies $/ \mathrm{mL}$, which allowed the search for HBV resistance mutations by the standardized method as described above. In addition, 90\% (73/81) had records in
HUPES, which allowed for a review of clinical and laboratory data. The sample showed a higher frequency $(56 \%)$ of males with a mean age (years) of $44.2 \pm 14.3$ (SD = standard deviation). It was observed that most patients are mono-infected with HBV and with fibrosis F1-F3.

Only $25 \%$ (18/73) of patients with chronic hepatitis B had a history of previous antiviral treatment or in progress. The treatment was administered in male predominantly patients (78\%) that were $\mathrm{HBeAg}$ positive (73\%), ALT altered (72\%), with fibrosis F1-F3 (100\%), according to the data obtained upon admission (Table 1).

A chart review was not possible in one patient. The $\mathrm{HBeAg}$ seropositivity and ALT levels were maintained practically unchanged between admission and pretreatment. One patient did not test for $\mathrm{HBeAg}$ before treatment, but this was positive upon admission. The average viral load of $\mathrm{HBV}$ was of $7.3 \pm 7.6 \mathrm{log} / \mathrm{mL}$, much greater than 2000 copies $/ \mathrm{mL}$ or $3 \mathrm{log} / \mathrm{mL}$, a value that is recommended by the Ministry of Health protocols as a standard for indication of treatment (Table 2).

The average duration of treatment was 3 years, the minimum was less than one year and maximum 11 years. Most patients were treated with a single treatment regimen (82\%) and monotherapy (78\%). In our series, ETV was the most frequently administered drugs (44\%), followed by TDF (39\%), INF (16\%), and LAM (16\%) (Table 2).

The timeline of 16 patients with their treatment history was represented. The oldest treated patient was admitted in 1998 (T-5), but only started treatment in 2012, waiting for 14 years. The time of monitoring and the start of treatment were influenced by individual 
TABLE 2 Clinical and laboratory data pretreatment of patients treated with antiviral drugs in HUPES, 2012-2015

\begin{tabular}{|c|c|c|}
\hline Characteristics & $N=18^{\mathrm{a}} \%$ & Average $\pm \mathrm{DP}$ \\
\hline \multicolumn{3}{|l|}{ Pretreatment } \\
\hline AgHBe pos. & & $10 / 14(71)$ \\
\hline ALT & & $72.3 \pm 67.2$ \\
\hline$>\mathrm{VR}=41 \mathrm{UI} / \mathrm{dL}$ & & $12 / 16(75)$ \\
\hline HBV-DNA (log/mL) & & $7.3 \pm 7.6$ \\
\hline \multicolumn{3}{|l|}{ Treatment history } \\
\hline Previous & & $3 / 17(18)$ \\
\hline In course & & 14/17 (82) \\
\hline Duration of treatment (year) & & $3.0 \pm 4.1$ \\
\hline Min.-Max. & & $<1-11$ \\
\hline \multicolumn{3}{|l|}{ Number schemes } \\
\hline 1 & & 14/17 (82) \\
\hline 2 & & $3 / 17$ (18) \\
\hline \multicolumn{3}{|l|}{ Type of regimen } \\
\hline Monotherapy & & 14/18 (78) \\
\hline Conjugada & & $4 / 18(22)$ \\
\hline \multicolumn{3}{|l|}{ Antiviral drug } \\
\hline INF & & $3 / 18(16)$ \\
\hline LAM & & $3 / 18(16)$ \\
\hline ETV & & $8 / 18(44)$ \\
\hline TDF & & 7/18 (39) \\
\hline
\end{tabular}

$\mathrm{DP}=$ standard deviation.

${ }^{\mathrm{a}}$ Total vary depending on availability of data.

clinical features and the availability of antiviral drugs. INF and/or LAM analogs were administered to patients who began treatment earlier. Insofar as other antiviral drugs with greater genetic barrier and less side effects were available, they were gradually being preferably used.

Amplification and sequencing of HBV DNA for research of resistance mutations was performed on all samples tested. Altogether, 81 contigs (KU 847676 to KU 847762) were analyzed with, the size of $1032 \mathrm{bp}$, which corresponds to the total area of the rt $\mathrm{P}$ gene domain. Among the isolates tested, the $\mathrm{A} 1$ genotype was the most prevalent (85.2\%) followed by the $\mathrm{A} 2$ genotype (4.9\%) F (6.2\%) and C1, D2, and D4 (1.2\% each).
Six isolates (7\%) have mutations associated with the development of resistance to nucleos( $\mathrm{t}$ )ide analogs in the rt $\mathrm{P}$ gene domain (genotypic resistance): two patients showed the pattern L180M + M204V and four had other standards (L80I + L180M + M204I, M204V + L80V + L180M, M204I, A194T).

All mutations were identified in isolates with genotype A. In addition, four strains with mutations in the $S$ gene mutations associated with the $\mathrm{P}$ rt gene domain were detected. This corresponds to a rate of $6 \%$ of vaccine escape mutations. Three cases presented the sl195M mutation and the sW196L mutation. Although these codons overlap only in the region of the rtM204V/I mutation, changes in the S gene were found only between the cases with the compensatory mutations rtL80I/V and rtL180M (Table 3).

Taking as the outcome, the occurrence of mutations was significantly associated to this event: positive for $\mathrm{HBeAg}$, co-infection with HIV and history of treatment for HBV and/or HIV (Table 4). Due to lack of data from some patients and the sample size, the impact of the pretreatment viral loads on the occurrence of resistance mutations was not possible to be evaluated.

\section{5 | DISCUSSION}

We found that the genotypic profile of the studied populations was very similar and presented the three genotypes (A, D, F) circulating in Brazil. ${ }^{12-14}$ Interestingly, a patient with genotype $\mathrm{C}$ was found, although this genotype is characteristic in the East Asian region, it has been described in Brazil, as of recently. ${ }^{15}$ Still, it observed a higher frequency of HBV infection in men and with an average age of 40 years. Data that corroborate the literature, which indicates a higher hepatitis $B$ infection rate in groups of men. ${ }^{13}$

The main resistance mutations are found between the amino acid positions 80 and 250 (M Ghany 2007). And mutations in the YMDD motif at position 204 are the most frequent and relevant to resistance to lamivudine. ${ }^{16,17}$

In the study population, we observed the presence of mutation of the following standards: L180M + M204V and four different patterns: L80I + L180M + M204I; L80V + L180M + M204V; M204I; A194T.

Among the factors which predispose $\mathrm{HBV}$ resistance to analogues, there are: the persistence of $\mathrm{HBsAg}$ for more than 6 months in serum

TABLE 3 Genotypic profile of patients with mutations of resistance to analogs nucleos(t)ídes

\begin{tabular}{|c|c|c|c|c|}
\hline \multirow[b]{2}{*}{ Case } & \multirow[b]{2}{*}{ Origin } & \multirow[b]{2}{*}{ Genotype } & \multicolumn{2}{|l|}{ Mutations } \\
\hline & & & Gene P & Gene S \\
\hline T-6 & BRA/BA/SSA & $\mathrm{A} 1$ & L80V + L180M + M204V & I195M \\
\hline $\mathrm{T}-17$ & BRA/BA/SSA & $\mathrm{A} 2$ & L180M + M204V & I195M \\
\hline T-18 & BRA/BA/SSA & $\mathrm{A} 2$ & L180M + M204V & I195M \\
\hline $\mathrm{N}-2$ & BRA/BA/SSA & $\mathrm{A} 1$ & L80I + L180M + M204I & W196L \\
\hline
\end{tabular}

$\mathrm{N}$, naíve patient; $\mathrm{T}$, treated patient. 
TABLE 4 Clinical and laboratory characteristics of patients with chronic hepatitis B with / without mutation seen at HUPES between 2012 and 2015

\begin{tabular}{|c|c|c|c|c|c|}
\hline \multirow[b]{2}{*}{ Characteristics } & \multicolumn{2}{|c|}{ With mutation } & \multicolumn{2}{|c|}{ Without mutation } & \multirow[b]{2}{*}{$P$} \\
\hline & $N=6^{b}$ & Average \pm SD & $N=75^{b}$ & Average \pm SD & \\
\hline $\mathrm{AgHBe}$ & & & & & 0.01 \\
\hline Neg. & 0 & & 44 & & \\
\hline \multicolumn{6}{|l|}{ HIV } \\
\hline Serum, negative & 1 & & 37 & & \\
\hline $\mathrm{ALT}, \mathrm{UI} / \mathrm{dL}$ & $83.5 \pm 19.0$ & & $72.8 \pm 74.3$ & & \\
\hline \multicolumn{6}{|l|}{ Level ALT } \\
\hline$>\mathrm{VR}=41 \mathrm{UI} / \mathrm{dL}$ & 3 & & 28 & & ns \\
\hline$A$ & 6 & & 65 & & \\
\hline No-A & 0 & & 8 & & \\
\hline Hist. treatment & & & & & 0.01 \\
\hline Treated & 4 & & 14 & & \\
\hline Naive & 1 & & 53 & & \\
\hline Antiviral drug & & & & & ns \\
\hline LAM & 1 & & 1 & & \\
\hline Others $^{a}$ & 2 & & 13 & & \\
\hline
\end{tabular}

SD, standard deviation; ns, not significant; nd, not determined; VR, Reference value; LAM, Lamivudine.

aSome patients were treated for HIV with other analogues nucleos(t)ídes.

${ }^{\mathrm{b}}$ Total vary depending on availability of data.

situation, which characterizes chronic hepatitis $B$, and elevated viral load and transaminases before the treatment and on the duration (time) of the treatment ${ }^{8}$ and the presence of $\mathrm{HBeAg}$ pre-treatment and co-infection with HIV.

In this study we observed a strong association of factors: history of treatment, pretreatment of $\mathrm{HBeAg}$ positive status, and co-infection with HIV to the development of the resistance mutation $(P=0.01$, $P=0.01$, and $P<0.01$, respectively).

As mentioned before, resistance mutations related to lamivudine are mainly in the YMDD motif. Because of this reason, M204V and $\mathrm{M} 204 \mathrm{l}$ are the most frequent resistance mutations to lamivudine. ${ }^{8,17,18}$ It is also reported that the M204V mutation reduces viral fitness when compared to M204I. By virtue of this characteristic, the M204V mutation is combined with the compensatory mutation L180M to enhance this replication capacity, while the M204I can be more easily found individually. $8,17,18$

Tenofovir is analogous with higher genetic barrier, so it has little or no associated resistance mutation. Recently, the A194T mutation has been described with a resistance mutation, in vitro, associated with the TDF. This mutation has been described in the literature in a HIV monoinfected case treated with TDF for 6 months. ${ }^{9}$ In our study, the patient who had the virus with this mutation was treatment-naive and had a viral load of $<2000 \mathrm{IU} / \mathrm{mL}$ or $3 \mathrm{log} / \mathrm{mL}$. Although there are still few studies, it is believed that the genotype may also have influence on the development of resistance to antiviral drugs, and genotype $D$ is the most frequent for M204I mutation in comparison to the genotype $A{ }^{13,17,18}$

In this work, all the mutations found were present in patients with genotype A. However the association analysis did not show statistically significant results.

The work also includes analysis of changes in the S gene, with impact on vaccine escape, associated with mutations in the RT. A rate of $6 \%$ of sequences was found to have vaccine escape mutations, lower than the rate reported in studies with patients coinfected with HIV. ${ }^{9}$ Those change for the group of patients coinfected with HIV and have the genotype $D$, and are in a prolonged treatment with lamivudine as risk factors for the development of these mutations. However, in this work, such mutations in the HBV consensus sequences of three patients coinfected with HIV and monoinfected was observed, all genotypes $A$.

In conclusion, we found a higher frequency of men that were HBeAg negative patients, $25 \%$, however, among patients treated for $\mathrm{HBeAg}$ positive, the percentage was higher, with $71 \%$. With respect to 
HBV genotyping, an increased prevalence of the genotype A1 (85.2\%) followed by the genotype A2 (4.9\%), F (6.2\%), and C1, D2, and D4 (1.2\% each) was observed. There was a rate of $7 \%$ of mutant strains resistant to nucleos $(\mathrm{t})$ ide analogs, and a strong association between the occurrence of resistance mutations for $\mathrm{HBV}$ in patients with coinfection for HIV in the treatment history, and negative anti-HBe was found. In the future, a study with an analysis of the level of viral quasispecies will be necessary.

Finally, given the results presented before therapy is initiated, it is extremely important to monitor the viral load and identify the resistance mutations to support clinical decisions about management of patients and prevent the emergence of resistant multi-viruses.

\section{ACKNOWLEDGMENTS}

This study is funded by FIOCRUZ-BA and Universal-MCTI/CNPq No. process: 478322/2012-7. In addition, we are thankful to the partner institutions LACEN-BA, for the exams, and infrastructure provided by the Hospital Universitário Professor Edgard Santos (HUPES).

\section{CONFLICT OF INTEREST}

None.

\section{REFERENCES}

1. Kane M. Global programme for control of hepatitis B infection. Vaccine. 1995;13:47-49.

2. WHO. Hepatitis B, countries or areas at risk. 2012. Available at: http:// www.who.int/mediacentre/factsheets/fs204/en/. Access: 2012.

3. Maddrey W C. Hepatitis B-an important public health issue. Clin Lab. 2001;47:51-55.

4. Locarnini S, Birch C. Antiviral chemotherapy for chronic hepatitis B infection: lessons learned from treating HIV-infected patients. J Hepat. 1990;30:36-550.

5. Duffy S, et al. Rates of evolutionary change in virus: patterns and determinants. Nature Publishing Group. 2008;9:267-276.

6. Martell ME, et al. Hepatitis $\mathrm{C}$ virus (HCV) circulates as a population of different but closely related genomes: quasispecies nature of $\mathrm{HCV}$ genome distribution. J Virol. 1992;66:3225-3229.
7. Chen S, Wang YM. Genetic evolution of structural region of hepatitis C virus in primary infection. Worl J Gastroenterol. 2002;8:686-693.

8. Thompson AJVA, et al. Lamivudine resistance in patients with chronic hepatitis B: role of clinical and virological factors. J Gastroenterol Hepatol. 2006;22:1078-1085.

9. Lacombe KB, et al. High incidence of treatment-Induced and vaccineescape hepatitis $B$ virus mutants among human immunodeficiency virus/hepatitis B-infected patients. Hepatology. 2013;58:913-922.

10. Stuyver L, De Gendt S, et al. A new genotype of hepatitis B virus: complete genome and phylogenetic relatedness. J Gen Virol. 2000; 81:67-74.

11. Rhee SY, et al. Hepatitis B virus reverse transcriptase sequence variant database for sequence analysis and mutation discovery. Antiviral Res. 2010;88:269-275.

12. Araujo NM, et al. High proportion of subgroup $A^{\prime}$ (genotype $A$ ) among brazilian isolates of hepatitis B virus. Arch Virol. 2004;149:1383-1395.

13. Bottecchia MS, et al. Hepatitis $B$ virus genotypes and resistance mutations in patients under long term lamivudine therapy: characterization of genotype G in Brazil. BMC Microbiol. 2008;8:1-10.

14. Gomes-Gouvêa MS, Ferreira AC, Teixeira R, et al. HBV carrying drugresistance mutations in chronically infected treatment-naive patients. Antivir Ther. 2015;20:387-395.

15. Bertolini DA, et al. Hepatitis $B$ virus genotypes from European origin explains the high endemicity found in some areas from southern Brazil. Infect Genet Evol. 2012;6:1295-1304.

16. Da Silva LC, da Fonseca LE, et al. Predictive factors for response to lamivudine in chronic Hepatitis B. Rev Inst Med Trop. 2000;42: 189-196.

17. Haddad RM, et al. Hepatitis B virus genotyping among chronic hepatitis $B$ patients with resistance to treatment with lamivudine in the city of Ribeirão Preto, State of São Paulo. Rev Soc Bras Med Trop. 2010;43:224-228.

18. Zöllner BP, et al. Viral features of lamivudine resistant hepatitis B genotypes A and D. Hepatology. 2004;39:42-50.

How to cite this article: dos Santos MIMA, Pacheco SR, Stocker A, et al. Mutations associated with drug resistance and prevalence of vaccine escape mutations in patients with chronic hepatitis B infection. J Med Virol.

2017;89:1811-1816. https://doi.org/10.1002/jmv.24853 